\title{
12. Specialist Communities in China's Aerospace Technology and Innovation System: The Cultural Dimension
}

Alanna Krolikowski

\section{Introduction}

Only two decades ago, China was a marginal player in the global aerospace industry. Today, the pace of China's space programs is unparalleled and it has joined the sector's leading ranks. China is the only country after the Soviet Union/Russia and the United States to independently send humans into orbit and a rover to touch down on the Moon. A Chinese station will likely soon be only the only long-term human habitat circling the Earth alongside the International Space Station. Within a decade, China could become only the second country in history to land a person on the Moon's surface. China already has the world's largest radio telescope and is building more large instruments. The country's advances in aeronautics are no less striking. A Chinese firm has disrupted the regional jet market and is poised to enter the large civil aircraft market, challenging the Airbus-Boeing duopoly. Chinese firms already produce advanced military aircraft that fly sensitive missions.

A permissive cause of these developments has been the growing wealth of the Chinese state. Top leaders have declared a political and ideological commitment to science and technology (S\&T) modernisation since at least the era of Deng Xiaoping. Yet, as recently as the mid-1990s, advocates of aerospace projects struggled to persuade top leaders that their efforts were worth a share of scarce public funds and fought for the very survival of their programs (Li 2013). Only in the past two decades have the central government's swelling coffers allowed the administrations of $\mathrm{Hu}$ Jintao and $\mathrm{Xi}$ Jinping to direct substantial resources towards these initiatives (Suttmeier 1980; Liu et al. 2011), as shown in China's accelerated increase in expenditure on research and development (Figure 12.1). 


\section{0 million}

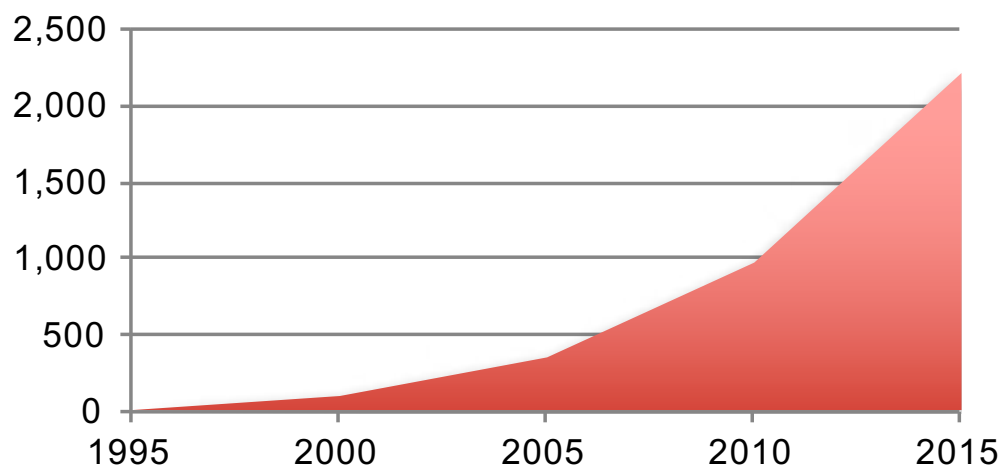

Figure 12.1 China's expenditure on research and development (renminbi) Source: NBS (2017).

While the central government's material support has made the pursuit of aerospace capabilities possible, it does not explain how these capabilities were achieved. A substantial body of scholarship in S\&T studies demonstrates that there are multiple pathways to technical achievement and innovation in the aerospace sectors (Zeitlin 1995; Montresor 2001; Keller and Samuels 2003; Pekkanen 2003; Hughes 2004; Pavelec 2004; Hickie 2006; Palmer 2006; Jeon 2010). Diverse configurations of policies, institutions and programs can produce engineering success. And, indeed, China's aerospace sectors illustrate that the country's innovation system accommodates a diversity of approaches to pursuing ambitious technology goals. This chapter examines why and how China's central government has pursued contrasting innovation strategies for developing national capabilities in two adjacent sectors with comparable features: civil commercial aircraft manufacture and civil commercial spacecraft manufacture. The approach to the former sector has stressed drawing in foreign knowledge and systems and embedding Chinese firms in global value chains, while the approach to the latter has prioritised developing indigenous technology to enhance national autonomy.

To grasp how the strategies in the two sectors diverged, it is helpful to keep in view the broader changes that have transformed China's science, technology and innovation system over the past four decades. These changes have allowed distinct communities of specialists to coalesce and influence the design and implementation of major innovation strategies. These communities have become powerful shapers of long-term policy in their respective domains and their policy input helps account for the variation in the strategies adopted for aircraft and spacecraft manufacture. 
The first part of this chapter surveys the institutional changes that have transformed China's technology and innovation system and, within it, the aeronautic and space sectors. The second part discusses the culturally distinct specialist communities that have emerged in these two sectors and how they have shaped policymaking to allow for the adoption of distinct sectoral strategies.

\section{The institutional setting}

China's pool of scientists and technologists is enormous and growing as a share of the country's workforce (Figure 12.2). Scholars have documented and debated the transformation of this stock of human capital, examining not only the input of newly skilled workers, but also their organisation into new structures (Saich 1989; Dickson 1998; Suttmeier and Cao 1999; Liu and White 2001; Huang et al. 2002; Cao 2003; Sleeboom-Faulkner 2006; Appelbaum et al. 2011). These studies examine how the reform and development of key institutions have structured the conduct of S\&T activities, revealing their contributions and limitations.

\section{Millions}

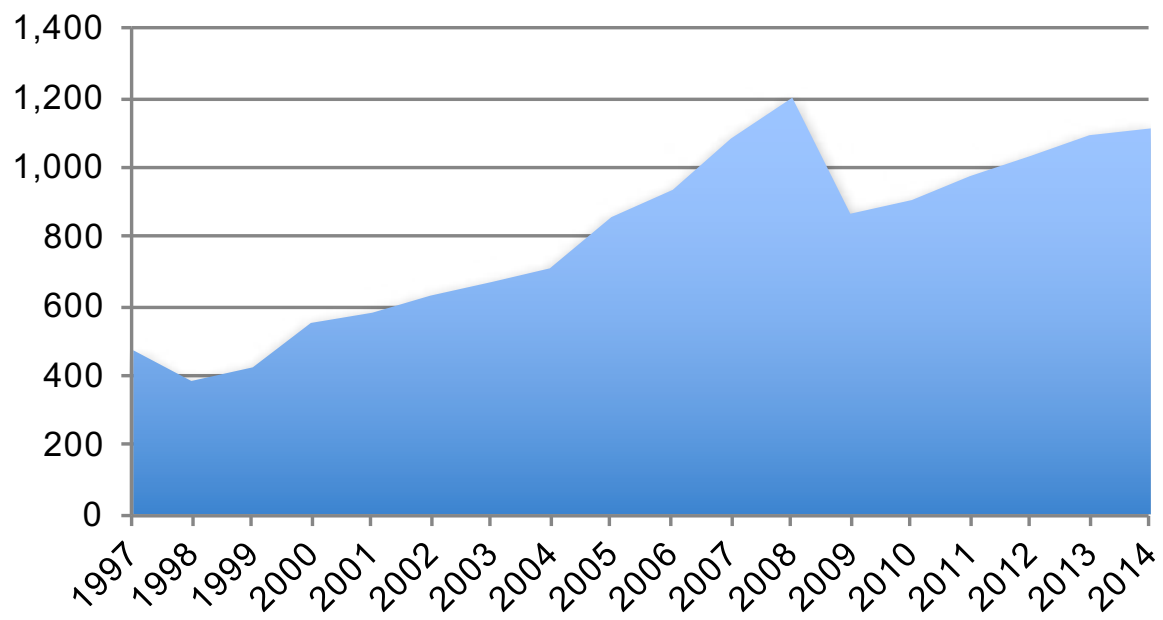

Figure 12.2 Researchers in research and development in China Source: World Bank (2017).

Often, these institutional changes have created conditions in which the impact on innovation of other inputs has been enhanced. The transformations have allowed China's aerospace S\&T establishment to make improved use of resources and more effectively seize opportunities presented by expanded government aerospace procurement and the technological upgrading of the broader economy. These trends - most apparent since the 1990s — include the institutionalisation of S\&T 
activities, the specialisation of the S\&T establishment into distinct functional and sectoral elements and the professionalisation of its workforce. The discussion below delineates the broad contours of these transformations as they have occurred across a range of sectors, including aeronautics and space.

\section{Institutionalisation}

'Institutionalisation' here refers to the process of creating and developing stable formal organisational and other processes for the implementation of S\&T policies and programs. Since 1978, China's innovation system has transformed from ad hoc, reactive and highly politicised project-driven decision-making and implementation to a system characterised by systematic, stable and coherent institutional mechanisms for developing and implementing major long-term S\&T strategies and, within them, medium- and short-term policies and programs (Suttmeier 1980; Simon and Goldman 1988; Saich 1989; Cheung 2011).

This institutionalisation of S\&T activities has occurred alongside, and in a mutually supportive fashion with, the institutionalisation of processes across other areas of policymaking within the Chinese state (Liu and White 2001). These include the broad domains of economic reform, public sector governance and defence modernisation.

Several features of this institutionalisation appear to have significantly enhanced the performance of technology-intensive equipment manufacturing industries, such as the manufacture of aircraft and spacecraft. Long-term strategies have provided stability and predictability in policies and programs. Systematic channels for the communication of expert advice to decision-makers have improved the quality of policymaking. The state's supervision of state-owned industrial groups has been refined and harmonised. The interface between equipment manufacturers and end users has improved. These features of the new institutional environment have also intensified interaction between specialists from different work units within the same sector, fostering the emergence of sector-wide specialist communities.

\section{Specialisation}

As the innovation system has grown, it has also differentiated internally. Since 2000, new research and development $(\mathrm{R} \& \mathrm{D})$ initiatives have proliferated, absorbing the swell of personnel and resources. These initiatives take the form of diverse projects, funds, regional development pushes and the building of institutions and facilities across almost every major segment of S\&T. The areas affected are diverse, ranging from nuclear engineering and shipbuilding to artificial intelligence. 
Today, the national innovation machine is active in almost every major area of S\&T that has an impact on economic or defence modernisation. Organisations dedicated to specific technical areas are now established across countless segments of S\&T. They have multiplied and expanded in scope (Figure 12.3). Certain large entities have also differentiated internally into subentities that focus on specific production segments or technical areas. In other words, expansion and diversification at the systemic level have co-occurred with specialisation or re-specialisation at the level of sectors, firms and units within them. Like broad institutionalisation, the proliferation of dedicated new entities has fostered the emergence of specialist communities in different sectors and subsectors.

\section{1,000 units}

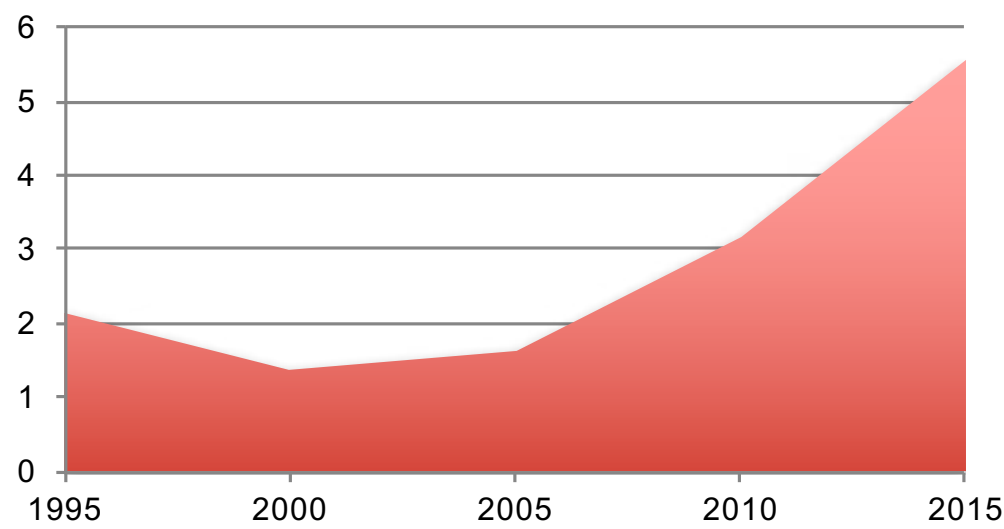

Figure 12.3 Research and development institutions in China Source: NBS (2017).

\section{Professionalisation}

Another factor contributing to the development of high-technology capabilities is the professionalisation of the S\&T workforce. In the late 1980s and beyond, major technology programs were led and sometimes created from scratch by elite scientists and engineers. The contributions of these figures, though monumental and enduring in their own right, depended on their personal status and connections to political and military leaders and factions. In general, S\&T programs were subject to shifting political winds-encountering adoption, funding and support or fiscal neglect, postponement and termination as they fell in and out of favour with non-technical decision-makers (Schneider 1988; Chang 1996; Feigenbaum 2003; Handberg and Li 2007; Schmalzer 2008; Andreas 2009). 
Since the 1980s, however, management at the higher echelons of this workforce has undergone three changes that have mitigated political interference, personalistic authority and erratic management.

The first is depoliticisation. Direct, politically motivated interference by top leaders in specific S\&T personnel appointments and activities (Schneider 1988; Handberg and Li 2007; Andreas 2009; Hu 2009; Luk 2015) all but disappeared by the end of the $\mathrm{Hu}$ administration. Even under the politicised anticorruption campaign of President $\mathrm{Xi}$ Jinping, which has targeted many large state-owned enterprises (SOEs) in high-technology sectors, aircraft and spacecraft manufacturers appear to have eluded significant leadership changes or other disruption. Today, at least within the aerospace sectors, major decisions appear to reflect not struggles over power and privilege within the state, but technical, fiscal or other factors.

The second change is de-personalisation. The fate of an S\&T program is far less closely tied with the professional or political fortunes of a single influential figure or group than it was only two decades ago (Lu 2005a; Li 2013). A class of scientific and technical elites has risen (relatively more) meritoriously to program management and other administrative roles (Cao 2004). Within programs, leadership changes are now more standardised. Personal attention from high-level leaders to S\&T programs remains a feature of the system (Besha 2010; Cheung 2016), as indicated by President Xi's continuing personal visits to key facilities, but no major aerospace program has recently suffered because of an influential individual's fall from grace.

The third change is routinisation. More robust mechanisms for proposing, adopting and implementing S\&T projects developed under former president $\mathrm{Hu}$ and persist today. The initiation of a program requires multiple layers of review before it reaches high-level decision-makers. ${ }^{1}$ Most programs are proposed at the top of a sectoral or subsectoral hierarchy on the basis of goals identified in the long-term central government plans (Liu et al. 2011). When this involves the acquisition of a large system, as in the case of a large defence aircraft program, leaders of the procuring units must translate goals set out in high-level strategies into concrete program objectives and, in turn, specific system requirements (Puska et al. 2011).

The processes of institutionalisation, specialisation and professionalisation have reshaped the setting for innovation, laying the foundations for more complex and demanding S\&T activities. These changes have also fostered the formation of specialist communities in particular sectors, to which we now turn. 


\section{Specialist communities}

A specialist is an individual professional in a given technology sector who possesses subject-matter expertise that those outside their sector lack. A specialist community is a collective of professionals active in a given sector who share not only this specialised technical knowledge, but also other basic assumptions about technology and the world around it (Rouse 1993). Experts within a sector often come to share a given world view comprising basic philosophical commitments. These assumptions are so widely accepted that they do not require explicit articulation. Because of their often tacit nature, these assumptions are sometimes called 'background knowledge' (Adler 1992; Adler and Pouliot 2011). These tacit understandings form the bedrock of a specialist community's culture. Members express and reinforce their background knowledge in a wide range of daily professional practices, including habits of speech and writing (Adler and Pouliot 2011). Sectoral experts' shared background knowledge, expressed in common practices, constitutes their community's specialist culture (Rouse 2003). China’s S\&T establishment comprises countless specialised sectors-from biotechnology to nanotechnology—whose experts form distinct specialist communities.

Elements of the specialist culture shared among members of such a community may transcend national boundaries, language barriers and occupational differences. Scientists, engineers, technicians, investors, lawyers and insurers often belong to a single specialist community. Websites, textbooks, academic journals, trade magazines and conference presentations carry representational practices across continents, diffusing them throughout a transnational specialist community, even while its members remain dispersed. What we observe, then, is not a peculiar 'Chinese' culture of science, technology and innovation, but many specialist cultures that exist within China's S\&T establishment and transcend its borders. In aerospace, for example, Chinese specialists' practices and understandings reflect their exposure to Soviet/Russian, US and European counterparts (Krolikowski 2015).

Within every high-technology sector, certain experts do not share the community's dominant stock of background knowledge and practices. In spite of these dissidents, a mainstream specialist culture is usually discernable within a community. When specialists differ on the mere specifics of policies or programs, rather than their basic direction, their disagreement is usually predicated on their common acceptance of more fundamental assumptions about their sector and their work.

Experts draw on this specialist culture when they describe and define their sector and its policy needs to policymakers. When specialists represent their sector in speech or writing, they rely on a set of representational practices—or habits of expression—-shared within their community. These discursive acts reflect and 
convey the underlying philosophical assumptions tacitly shared within the specialist community. Representational practices are important because they 'anchor' other practices, such as programmatic and regulatory practices (Swidler 2001).

Specialist communities shape the S\&T system because they discursively constitute distinct sectors as sites requiring particular types of policies. In the process of depicting their sector to policymakers, specialists also impart philosophical assumptions that tacitly lend support to some policy measures over others. Sectoral specialists define their sectors as objects of policy. Their acts of speech and illustration are not merely representational, but also productive of their sectors and technologies (Rouse 1993; MacKenzie 2006).

China's innovation system is home to specialist communities that play these roles. Within the aerospace sectors, at least five conditions help form and maintain tightknit specialist communities:

1. Barriers to the free circulation of ideas between sectoral experts and outsiders foster an insular specialist culture. Examples include secrecy rules and the program specificity of technical knowledge, both of which characterise work in the defence-industrial conglomerates to which China's aerospace firms belong. ${ }^{2}$

2. Barriers to the entry and exit of individual professionals preserve a specialist community's internal culture. China's aeronautic and space specialists tend to spend their entire careers within their sector, as do their counterparts in many countries, in part because programs have long lifetimes and because attractive opportunities outside a few large industrial groups are scarce. ${ }^{3}$

3. Sectors dominated by large firms and organisations, such as the behemoth aerospace industrial groups, are more likely to have robust internal cultures than sectors fragmented into many smaller entities. Large organisations provide conduits for the maintenance and propagation of such cultures.

4. Hierarchical structures nurture the emergence and consolidation of specialist cultures within organisations. Hierarchies supply role models and reward individuals for the correct performance of a community's cultural practices. Large SOEs feature such structures.

5. Organisations within which professional training and interaction take the form of master-apprentice relationships-for example, supervisor-student, laboratory director-technician, administrative patron-client-are effective at socialising new entrants into their culture (Chang 1996; Qiu 2009; Wang 2011). The aerospace industry features such interactions. ${ }^{4}$

2 Interviewee 25-43-20, interview with space expert from a space-sector operational organisation, 2010.

3 Interviewee 20-36-42, interview with space expert from Chinese research institution, 2010.

4 Interviewee 25-43-20. 


\section{Scientists and engineers in policymaking}

Specialist communities are worth examining because they are the actors most directly responsible for China's scientific and technological output. They also have an impact on policies and programs, which ultimately shape the long-term prospects for Chinese innovation. Several conditions grant scientists and engineers unique roles in policymaking.

Scientists and engineers form a reservoir of technical expertise for policymakers to consult. Policymakers rarely have any direct experience of the particular sector at stake when devising innovation strategies, so they rely on specialists to interpret these for them. Policymaking bureaucracies tap experts to monitor trends, define problems and policy options and make recommendations. Decision-makers draw on specialist insights when they adopt, evaluate and reform policy for a given technology sector.

Mechanisms exist to channel expert advice to high-level political decision-makers (Halpern 1988). Experts brief leaders, write reports and present at conferences for policymakers who prepare plans and strategies for the sector (Halpern 1988; Zhu 2009)..$^{5}$

Since the 1950s, individual elite scientists and engineers have had the ear of senior Chinese leaders, such as Zhou Enlai and Nie Rongzhen (Feigenbaum 2003; Besha 2010; $\mathrm{Li} 2013)$. Some have cultivated and used this influence to pursue major S\&T projects of their own design and initiative.

Scientific and technical elites derive power and influence from their very status as experts. This is true almost everywhere, but especially so in post-Mao China's technocratic context (Cheng and White 1990; Hua 1995; Greenhalgh 2003). Historically, this status has afforded aerospace experts substantial policy influence, extending even into domains far outside their area of formal training, such as agriculture and family planning (Chang 1996; Greenhalgh 2005).

These factors combine to give China's aeronautic and space experts significant input into and influence over policymaking in their sectors.

5 Interviewee 40-27-18, interview with space expert from Chinese research institution, 2010; Interviewee 24-1941, interview with export control specialist at a Chinese think tank, 2010. 


\section{Aeronautic and space specialists}

Aeronautic and space experts have sometimes wielded this influence as individuals or interest groups. However, they have had the most enduring and far-reaching impact as specialist communities shaping the landscape within which innovation projects take place. China's aeronautic and space experts belong to distinct specialist communities, each of which is held together by a particular internal culture. As aeronautic and space experts represent their sectors to policymakers, they also implicitly convey distinct policy prescriptions, helping to shape overarching sectoral innovation strategies.

The central government's strategies for developing the nation's aeronautic and space sectors differ markedly. The approach to developing aircraft manufacture has been premised on trade and industrial collaboration with foreign firms since at least the early 1990s. In contrast, the strategy for the spacecraft sector has prioritised autonomously developing critical systems at home and the domestic vertical integration of the national industrial base for several decades, since at least the time of the Sino-Soviet split. To a large degree, these differences reflect the distinct opportunities for trade and foreign collaboration available to Chinese firms and agencies, which have been far more numerous and substantial in aeronautics than in space. However, a close reading of specialist pronouncements reveals that the distinct approaches adopted in each sector long predate Chinese firms' differential access to international technology. This situation suggests that aeronautic and space specialists have understood and depicted the international landscapes before them in fundamentally different ways for several decades.

\section{Aeronautic specialists and policy}

Within China, aeronautic specialists are found in a range of organisations spanning SOEs in the defence sector-namely, the Aviation Industry Corporation of China (AVIC) and its arm's-length civil subsidiary, the Commercial Aircraft Corporation of China (Comac) - government agencies, the military and technical universities (Deng et al. 1988; Allen et al. 1995; Goldstein 2006; MIIT 2009; Cliff 2010).

China's aeronautic experts belong to a larger transnational community of aircraft technology specialists, sharing its basic assumptions and discursive practices. Like their counterparts in other countries, China's aeronautic specialists tend to regard aircraft technologies as intrinsically global products (Y. Zhang 2007). Experts define modern aircraft as comprising elements designed and made in different countries. They describe global production networks as the most advanced and self-evident mode of manufacture for this industry. These ideas are rooted in a benign view 
of the international political economy and world markets. As aeronautic experts explain it, competition between firms and national industries drives innovation and benefits consumers (Chen 2008).

That understanding finds parallels in aeronautic experts' depictions of global aviation activities and the physical environment of flight. Aeronautic engineers tend to envision global airspace as a single transboundary domain. They describe air transportation systems and infrastructure as ideally and naturally forming a seamless global whole that transcends national borders. This view of the aviation environment extends to experts' representations of aircraft operations, regulation and production, all of which require transnational integration in a similar manner (Y. Zhang 2007).

These ideas shape Chinese aeronautic specialists' shared expectations of how their national industry should evolve. Leading experts consistently explain that, like the world's leading airplane manufacturers, Airbus and Boeing, China's national champions should establish global supply chains and facilities to support client airlines all over the world (Zhang 2008; AVIC 2015). These experts also represent offset arrangements with firms in other countries whose airlines will buy their aircraft as a natural part of this evolution. ${ }^{6}$

These views are consistent with other, more fundamental understandings shared by Chinese and international aeronautic specialists. Their perspectives on global trade and transnationally distributed production rest on what could be termed an 'economic' or instrumental philosophy of technology. In this understanding, technical artefacts, such as airliners and aircraft engines, reflect the demands of their social context and the choices of their designers and makers (Y. Zhang 2007; Chen 2008). Aeronautic technology does not evolve according to a logic of its own, but rather develops in response to market pressures, client demands and other human or social factors (Qi and Cheng 2006). Engineers and inventors are the shapers of these devices, which they tailor to meet the needs of their time and place (Yao 1996; Liu 2007).

These understandings reach the high-level policymakers who decide long-term innovation and industrial strategies for the aircraft sector. Aeronautic experts convey their ideas through the analyses and other technical input they supply to policymakers. When experts represent their sector as endowed with specific features, they implicitly prescribe national policies consistent with these characteristics.

When aeronautic experts depict their industry and technologies as inherently global, they represent their sector as one requiring policies that foster trade, transnational industrial integration and intergovernmental civil cooperation (Guo 2000; Lu 2005b). These include measures to facilitate the transboundary sale

6 Interviewee 18-00-18, interview with senior Chinese aircraft industry professional, 2010. 
of aircraft articles and investment in aircraft facilities, to harmonise global standards for products and to support partnerships with leading foreign firms (Yu 2009; Mecham and Anselmo 2011). When aircraft items are represented in this way, an insistence on developing and using indigenous technology for the sake of achieving national technological autonomy appears counterproductive and self-limiting. Instead, experts' depictions prioritise easing the inbound and outbound movement of aeronautic articles to China, attracting optimal foreign partners and, ultimately, ensuring the embedding of Chinese firms in global value chains (Frenken 2000; Bowen 2007; Raska and Krolikowski 2013).

These representations in turn support a sectoral strategy with particular features. First, a goal of China's aeronautics strategy has been to integrate Chinese firms into transnational industrial networks at optimal nodes (Grevatt 2012). This approach obviates the total vertical integration of aircraft manufacture within domestic firms (Tyroler-Cooper and Peet 2011). The strategy does not aim at straightforward import substitution, as indicated by the long-term targets of between 10 and 30 per cent indigenous content on the ARJ21 and C919 domestic airliner programs (Lu 2005a). ${ }^{7}$ Instead, inserting Chinese firms into transnational networks requires their selective specialisation in high value-added products for both domestic and global markets, alongside the importation and outsourcing of other components and services (Perrett 2009b). The desired end goal is a qualified substitution of high value-added imports with indigenous products in combination with imports and foreign-based industrial collaboration in selected areas (Perrett 2009a; Anselmo et al. 2011). For example, one long-term objective is to develop select national capabilities in commercial aircraft engine manufacture (Central People's Government 2009).

In this vision, AVIC will develop the regionally and globally distributed production processes of today's global top-tier aircraft manufacturers (AVIC 2015). Within this sectoral strategy, the measure of success is twofold: both the technological output and the export success of Chinese firms matter. For these experts, producing viable aircraft domestically is a priority of this approach, but emphasis is also placed on making AVIC entities into profitable, competitive export-oriented businesses. ${ }^{8}$ The result is a sectoral strategy with particular features that remains largely uncontested, even while markedly different policies are adopted in the adjacent space sector.

\section{Space specialists and policy}

China's space experts belong to their own distinct community and work across a vast range of institutions comparable to those found in the aircraft industry. These include two large state-owned defence-industrial groups, the Chinese Aerospace 
Science and Technology Corporation (CASC) and the Chinese Aerospace Science and Industry Corporation (CASIC), several government agencies, military entities and technical universities and research institutes (Sun 2007a; Ma 2011).

China's space experts share a specialist culture with space experts in other countries (Miller 2002), but their world view is unlike that of aeronautic specialists. When space experts look beyond their own borders, they see a hierarchical system of competing national industrial bases, each one's position dictated by its mastery of critical technologies. ${ }^{9}$ State power and the strength of industry are intertwined in this view, so industrial capabilities remain divided by national boundaries. ${ }^{10}$ The natural state of affairs in the space sector is for firms to engage in research, development and production activities within the borders of the country in which they are headquartered and with partners from the same country or, at most, close allies. National industrial bases compete on all fronts.

In these experts' depictions, the prognosis for the global space sector is its inevitable and persistent fragmentation into distinct national industrial bases. Given the sector's strategic role, a rising power must assure its independent access to and utilisation of the space environment by developing an industry of its own (Huang 2006, 2007).

These ideas imply a theory of world politics within which technological factors decide interstate struggles for security and dominance. To space experts, technological breakthroughs are the engines of world history. Advances in space systems are chief among these, bringing revolutionary changes to international politics and other social phenomena (Liu et al. 1996; Chang 2004). For example, in this view, the advent of space weapons has transformed the international system, creating runaway dynamics that governments and militaries cannot control (Zhang 2005; Huang 2006; Dai 2007; Peoples 2008a). Thus, unlike aeronautic experts, space specialists express deterministic and structural assumptions about space technology and its impact on society (Liang 2002; Dai 2007; Ma 2008; Peoples 2008b). While recognising that technological change has many sources, space experts assume that at least one of them is a momentum internal to technology itself (Huang 1999). They often represent technical processes as eluding human control. Technological change proceeds according to its own internal logic, which largely resists management by humans (Xu 2007). Technology advances and the social environment responds (Liu et al. 1996).

This hostile landscape in view, Chinese specialists have interpreted the tightening in 1999 of US restrictions on exports of space items to China as part of a US strategy to suppress China's peaceful rise (Liao 2006; Ning et al. 2006). In this understanding, tight US controls on space exports to China have not only denied

9 Interviewee 19-36-43, interview with space expert from an academic institution, 2010.

10 Interviewee 25-43-20. 
it trade opportunities, but also serve a larger US strategy to block China's national rejuvenation: a 'space containment policy' targeting China's core development and security interests (Zhang 2003; Communist Party Member 2008). This 'space embargo' constrains China's economic advance by excluding it from world markets for high-technology goods and, worse, stifles its societal and defence modernisation (Ma 2008). These depictions underpin and rationalise policies to rapidly and autonomously develop capabilities in civil, commercial, military, and intelligence space (Liao 2006; Sun 2006, 2007b; Q. Zhang 2007).

The long-term ideal, then, is national control over critical processes in satellite and launch vehicle manufacture and operation (State Council 2006). This goal demands the near-total vertical integration of manufacture within a national system of firms. The objective of sectoral policy is building a holistic industrial base within China, while selectively pursuing international cooperation projects where they bring significant benefits, but carry few risks (Q. Zhang 2007; Leading Party Group of CASC 2009). Foreign partners' inputs can supplement, but not substitute for or interfere with, homegrown capabilities (Liang 2002; Lan 2007). Success for CASC and CASIC means mission success and its corollary, technological achievement (Guo 2007). Business performance is a distantly secondary objective. ${ }^{11}$ Reforms of these conglomerates serve the objective of enhancing their technological output, rather than their profitability or corporate governance for its own sake. Exports are sought and represent industrial achievements, but they are not fundamental goals of the overarching sectoral development strategy.

Table 12.1 Technological development and innovation strategies in China's aerospace sectors

\begin{tabular}{|l|l|l|}
\hline Feature & Aeronautics & Space \\
\hline $\begin{array}{l}\text { Expected structure of } \\
\text { global industry }\end{array}$ & Transnational industrial integration & International industrial fragmentation \\
\hline $\begin{array}{l}\text { Form of industrial } \\
\text { structure sought }\end{array}$ & $\begin{array}{l}\text { Import substitution goals qualified, } \\
\text { not absolute } \\
\text { Vertical integration is not the end goal } \\
\text { AVIC to enter global industry at } \\
\text { particular nodes }\end{array}$ & $\begin{array}{l}\text { Total in-country vertical integration } \\
\text { National control over all critical } \\
\text { through to operations } \\
\text { Requires a holistic industrial base } \\
\text { within China }\end{array}$ \\
\hline $\begin{array}{l}\text { Relationship to } \\
\text { foreign technology } \\
\text { and suppliers }\end{array}$ & $\begin{array}{l}\text { AVIC to produce in global networks } \\
\text { Expect offsets, localisation of } \\
\text { manufacturing in client states } \\
\text { Seek stable supply chains - a means } \\
\text { to this are international standards }\end{array}$ & $\begin{array}{l}\text { Foreign inputs supplement, but never } \\
\text { substitute for, homegrown inputs }\end{array}$ \\
\hline $\begin{array}{l}\text { Vision of success for } \\
\text { major firms }\end{array}$ & $\begin{array}{l}\text { Exports matter: AVIC's success } \\
\text { measured in terms of both } \\
\text { technology output and business } \\
\text { performance }\end{array}$ & $\begin{array}{l}\text { Success for CASC and CASIC } \\
\text { means mission success and } \\
\text { technological achievement; business } \\
\text { performance is secondary }\end{array}$ \\
\hline
\end{tabular}

11 Interviewee 25-43-20. 
Through their representations, China's aeronautic and space specialists constitute their sectors as objects requiring specific policies. In the aeronautic sector, these policies foster global trade and cooperation. In the space sector, they constrain trade and cooperation, while prioritising the development of indigenous capabilities (Table 12.1).

\section{Conclusion}

China now has perhaps the world's most rapidly advancing space program and is poised to enter the technologically demanding large-carrier segment of the global aircraft industry. Within this evolving innovation system, clusters of experts, sharing specialised knowledge and a particular specialist culture, have coalesced. These communities are significant actors within the S\&T system and shapers of innovation policy.

China's specialist communities exert a diffuse and indirect impact on long-term innovation strategies. Experts participate in policymaking as authorities on their subject matter and technical domain. In the process, they perform representational practices that produce their sectors as specific sites for state action. These practices communicate not only experts' technical knowledge, but also their tacit policy recommendations. They reflect the specialist community's culture. Aeronautic and space experts illustrate these processes. Through their representations, these specialists create the enabling conditions for the innovation strategy adopted in each sector. Aeronautic specialists represent their sector as requiring an approach that draws in foreign knowledge and systems and embeds Chinese firms in global value chains. In contrast, space experts depict their sector as demanding a strategy that prioritises developing indigenous technology to enhance national autonomy. These specialists thus define the range of policies and outcomes that policymakers in each sector consider plausible and feasible, in the process setting the parameters on what kind of innovation strategy is possible in their domain. Through their representational practices, specialists produce agreement on the ends and means of policy.

\section{References}

Adler, E. (1992), The emergence of cooperation: National epistemic communities and the international evolution of the idea of nuclear arms control, International Organization 46: 101-45. doi.org/10.1017/S0020818300001466.

Adler, E. and Pouliot, V. (2011), International practices, International Theory 3(1): 1-36. doi.org/10.1017/S175297191000031X. 
Allen, K. W., Krumel, G. and Pollack, J. D. (1995), China's Air Force Enters the 21st Century, Santa Monica, CA: Rand Corporation.

Andreas, J. (2009), Rise of the Red Engineers: The Cultural Revolution and the origins of China's new class, Stanford, CA: Stanford University Press.

Anselmo, J. C., Mecham, M. and Perrett, B. (2011), Made in China: Airbus's Tianjin assembly plant replicates European quality, but at a higher cost, Aviation Week \& Space Technology, 25 April.

Appelbaum, R. P., Parker, R. and Cao, C. (2011), Developmental state and innovation: Nanotechnology in China, Global Networks 11(3): 298-314. doi.org/10.1111/j.1471-0374.2011.00327.x.

Aviation Industry Corporation of China (AVIC) (2015), AVIC Corporate Strategy. 7 September. Available from: www.avic.com/en/aboutus/corporatestrategy/index. shtml.

Besha, P. (2010), Policy making in China's space program: A history and analysis of the Chang'e Lunar Orbiter Project, Space Policy 26(4): 214-21. doi.org/10.1016/j.spacepol.2010.08.005.

Bowen, J. T., jr, (2007), Global production networks, the developmental state and the articulation of Asia Pacific economies in the commercial aircraft industry, Asia Pacific Viewpoint 48(3): 312-29. doi.org/10.1111/j.14678373.2007.00350.x.

Cao, C. (2003), Digital dragon: High-technology enterprises in China, The China Quarterly (2003): 538-39.

Cao, C. (2004), China's Scientific Elite, New York: RoutledgeCurzon.

Central People's Government of the People's Republic of China (Central People's Government) (2009), When will large domestic aircraft have a 'Chinese heart'? [in Chinese], 20 January, Central People's Government of the People's Republic of China, Beijing. Available from: www.gov.cn/fwxx/kp/2009-01/20/ content_1209835.htm.

Chang, I. (1996), Thread of the Silkworm, New York: Basic Books.

Chang, X. (2004), Military Astronautics, [in Chinese], 2nd edn, Beijing: National Defense Industries Press.

Chen, D. (2008), Discussion of Aviation, [in Chinese], Beijing: National Defense Industries Press. 
Cheng, L. and White, L. (1990), Elite transformation and modern change in Mainland China and Taiwan: Empirical data and the theory of technocracy, The China Quarterly 121: 1-35. doi.org/10.1017/S0305741000013497.

Cheung, T. M. (2011), The Chinese defense economy's long march from imitation to innovation, Journal of Strategic Studies 34(3): 325-54. doi.org/10.1080/0140 2390.2011 .574976 .

Cheung, T. M. (2016), The rise of the Chinese national security state under Xi Jinping, CPI Analysis, 15 December, China Policy Institute, Nottingham, UK. Available from: cpianalysis.org/2016/12/15/the-rise-of-the-chinese-national-security-stateunder-xi-jinping/.

Cliff, R. (2010), The development of China's air force capabilities, Testimony to the US-China Economic and Security Review Commission, Washington, DC.

Communist Party Member (2008), China says 'no' to space hegemony, [in Chinese], Communist Party Member (4): 25.

Dai, X. (2007), Space: War's ultimate high ground, [in Chinese], Contemporary Military Digest, Reprinted from China Defense Daily, 30 January 2007.

Deng, L., Ma, H. and Wu, H. (eds) (1988), Contemporary China's Aviation Industry, [in Chinese], Beijing: China Social Sciences Press.

Dickson, D. (1998), Back on track: The rebirth of human genetics in China, Nature 396(6709): 303-6. doi.org/10.1038/24470.

Feigenbaum, E. (2003), China's Techno-Warriors: National security and strategic competition from the nuclear to the information age, Stanford, CA: Stanford University Press.

Frenken, K. (2000), A complexity approach to innovation networks: The case of the aircraft industry (1909-1997), Research Policy 29(2): 257-72. doi.org/10.1016/S0048-7333(99)00064-5.

Goldstein, A. (2006), The political economy of industrial policy in China: The case of aircraft manufacturing, Journal of Chinese Economic and Business Studies 4(3): 259-73. doi.org/10.1080/14765280600991628.

Greenhalgh, S. (2003), Science, modernity, and the making of China's one-child policy, Population and Development Review 29(2): 163-96. doi.org/10.1111/ j.1728-4457.2003.00163.x.

Greenhalgh, S. (2005), Missile science, population science: The origins of China's one-child policy, The China Quarterly (182): 253-76. doi.org/10.1017/ S0305741005000184. 
Grevatt, J. (2012), AVIC boss eyes M\&A activity and teaming to grow 'global industrial chain', Jane's Defence Weekly, 19 November.

Guo, B. (2007), Milestones in China's space development: 'China's Space Activities' white paper, [in Chinese], Aerospace China, May.

Guo, E. (2000), Development of and responses to aircraft manufacturing technology, [in Chinese], Aircraft Manufacturing Technology 6: 16-20.

Halpern, N. M. (1988), Scientific decision making: The organization of expert advice in post-Mao China, in D. F. Simon and M. Goldman (eds), Science and Technology in Post-Mao China, pp. 157-74. Cambridge, Mass.: Harvard University Press.

Handberg, R. and Li, Z. (2007), Chinese Space Policy: A study in domestic and international politics, London: RoutledgeCurzon.

Hickie, D. (2006), Knowledge and competitiveness in the aerospace industry: The cases of Toulouse, Seattle and north-west England, European Planning Studies 14(5): 697-716. doi.org/10.1080/09654310500500254.

Hu, D. (2009), China and Albert Einstein: The reception of the physicist and his theory in China, 1917-1979, Cambridge, Mass.: Harvard University Press.

Hua, S. (1995), Science, scientism and humanism, in S. Hua, Scientism and Humanism: Two cultures in post-Mao China, pp. 9-32, Albany, NY: State University of New York Press.

Huang, J., Rozelle, S., Pray, C. and Wang, Q. (2002), Plant biotechnology in China, Science 295(5555): 674-6. doi.org/10.1126/science.1067226.

Huang, Z. (1999), Reflecting upon space strategy for our country in the early 21 st century, [in Chinese], Journal of Institute of Command and Technology 10(6): 1-5.

Huang, Z. (2006), Space weaponisation and space deterrence, [in Chinese], Studies in International Technology and Economy 9(1): 24-8.

Huang, Z. (2007), Space Science and Technology and Society: The fourth wave, [in Chinese], Guangzhou: Guangdong Education Publishing House.

Hughes, T. P. (2004), Human-Built World: How to think about technology and culture, Chicago: University of Chicago Press.

Jeon, C. (2010), Technologies of the operator: Engineering the pilot in the US and Japan, 1930-1960, Thesis, Massachusetts Institute of Technology, Cambridge, Mass. 
Keller, W. W. and Samuels, R. J. (eds) (2003), Crisis and Innovation in Asian Technology, New York: Cambridge University Press.

Krolikowski, A. (2015), Specialist communities: People and cultures in China's defense science and technology system, Research Brief, University of California Institute on Global Conflict and Cooperation, La Jolla, CA.

Lan, B. (2007), China's 'Beidou' breaks Western space monopoly, [in Chinese], Communist Party Member.

Leading Party Group of Chinese Aerospace Science and Technology Corporation (CASC) (2009), An exploit cast in reform and opening: The achievements, experience and prospects of our country's space development, [in Chinese], Aerospace China, January.

Li, C. (2013), The Chinese GNSS: System development and policy analysis, Space Policy 29: 9-19. doi.org/10.1016/j.spacepol.2012.11.001.

Liang, S. (2002), Long March Toward Space, [in Chinese], Beijing: China Astronautics Publishing House.

Liao, C. (2006), Commentary on the state of the new round of international space competition, [in Chinese], International Outer Space (7): 1-6.

Liu, F.-c., Simon, D. F., Sun, Y.-t. and Cao, C. (2011), China's innovation policies: Evolution, institutional structure, and trajectory, Research Policy 40(7): 917-31. doi.org/10.1016/j.respol.2011.05.005.

Liu, J., Bai, B.-a. and Liu, J. (eds) (1996), Space Technology and Modern Society, [in Chinese], Beijing: China Astronautics Publishing House.

Liu, X. and White, S. (2001), Comparing innovation systems: A framework and application to China's transitional context, Research Policy 30(7): 1091-114. doi.org/10.1016/S0048-7333(00)00132-3.

Liu, Y. (ed.) (2007), China's Aviation History, [in Chinese], 2nd edn, Changsha, China: Hunan Science and Technology Press.

Lu, F. (2005a), Reflections on our country's large aircraft development strategy, [in Chinese], China's Soft Sciences: 10-16.

Lu, F. (2005b), Research report on China's large aircraft development strategy, [in Chinese], Business Affairs Weekly, 20 March.

Luk, Y. L. C. (2015), A History of Biophysics in Contemporary China, Heidelberg, Germany: Springer. doi.org/10.1007/978-3-319-18093-9. 
Ma, X. (2008), Develop space manufacturing, serve the national economy, spur on social progress, [in Chinese], China Aerospace, May: 3-7.

Ma, X. (2011), Space Science and Technology Personnel's Journey to Maturity, [in Chinese], Beijing: China Astronautics Publishing House and China Aerospace Science and Technology Corporation.

MacKenzie, D. A. (2006), An Engine, Not a Camera: How financial models shape markets, Cambridge, Mass.: MIT Press. doi.org/10.7551/ mitpress/9780262134606.001.0001.

Mecham, M. and Anselmo, J. C. (2011), Aviation's 'learnaholics': China has the size, money and interest to engage and challenge Western companies, Aviation Week \& Space Technology, 25 April.

Miller, T. E. (2002), Epistemic communities in the space-policy arena: Evidence of their existence, their evolution, and their influence on policy, $\mathrm{PhD}$ thesis, University of Colorado, Denver.

Ministry of Industry and Information Technology of the People's Republic of China (MIIT) (2009), Overview of China's Civil Aviation Industry Enterprise Units, [in Chinese], Beijing: Aviation Industry Press.

Montresor, S. (2001), Techno-globalism, techno-nationalism and technological systems: Organizing the evidence, Technovation 21(7): 399-412. doi:10.1016/ S0166-4972(00)00061-4.

National Bureau of Statistics of China (NBS) (2017), Annual Data: Statistics database. Available from: www.stats.gov.cn/english/statisticaldata/AnnualData/.

Ning, L., Wang, C. and Rong, H. (2006), Confrontation in Space, [in Chinese], Beijing: Military Affairs Literature Publishing House.

Palmer, S. W. (2006), Dictatorship of the Air: Aviation culture and the fate of modern Russia, Cambridge: Cambridge University Press.

Pavelec, S. M. (2004), The development of turbojet aircraft in Germany, Britain, and the United States: A multi-national comparison of aeronautical engineering, 1935-1946, PhD thesis, Ohio State University, Columbus.

Pekkanen, S. (2003), Picking Winners? From technology catch-up to the space race in Japan, Stanford, CA: Stanford University Press.

Peoples, C. (2008a), Assuming the inevitable? Overcoming the inevitability of outer space weaponization and conflict, Contemporary Security Policy 29(3): 502-20. doi.org/10.1080/13523260802514811. 
Peoples, C. (2008b), Sputnik and 'skill thinking' revisited: Technological determinism in American responses to the Soviet missile threat, Cold War History 8(1): 55-75. doi.org/10.1080/14682740701791334.

Perrett, B. (2009a), Nosing ahead, Aviation Week \& Space Technology, 14 September: 26-7.

Perrett, B. (2009b), Cheaper by design, Aviation Week \& Space Technology, 14 September: $28-9$.

Puska, S. M., McReynolds, J. and Geary, D. (2011), China's military representatives: Striving toward professional contracting and procurement, SITC Research Brief No. 21, Institute on Global Conflict and Cooperation, University of California. Available from: escholarship.org/uc/item/8kb3g12j.

Qi, X. and Cheng, Z. (eds) (2006), The Birth and Development of Aircraft, [in Chinese], Beijing: National Defense Industries Press.

Qiu, J. (2009), Obituary: Qian Xuesen (1911-2009), Nature 462(7274): 735. doi.org/10.1038/462735a.

Raska, M. and Krolikowski, A. (2013), China's military aviation industry: In search of innovation, SITC Research Brief No. 2013-5, Institute on Global Conflict and Cooperation, University of California. Available from: escholarship.org/uc/ item/8t12095f.

Rouse, J. (1993), What are cultural studies of scientific knowledge? Configurations 1(1): 1-22. doi.org/10.1353/con.1993.0006.

Rouse, J. (2003), How scientific practices matter: Reclaiming philosophical naturalism, Isis 94(4): 791-2.

Saich, T. (1989), China's Science Policy in the 80s, Manchester: Manchester University Press.

Schmalzer, S. (2008), The People's Peking Man: Popular science and human identity in twentieth-century China, Chicago: University of Chicago Press. doi.org/10.7208/chicago/9780226738611.001.0001.

Schneider, L. (1988), Learning from Russia: Lysenkoism and the fate of genetics in China, 1950-1986, in D. F. Simon and M. Goldman (eds), Science and Technology in Post-Mao China, pp. 45-68. Cambridge, Mass.: Harvard University Press.

Simon, D. F. and Goldman, M. (eds) (1988), Science and Technology in Post-Mao China, Cambridge, Mass.: Harvard University Press.

Sleeboom-Faulkner, M. (2006), The Chinese Academy of Social Sciences, Boston: Brill. 
State Council of the People's Republic of China (State Council) (2006), Government White Papers: China's space activities in 2006, Beijing: Information Office of the State Council of the People's Republic of China. Available from: www.china.org. $\mathrm{cn} /$ english/features/book/183672.htm.

Sun, L. (2006), The brilliant achievements and development strategy of China's space sector, [in Chinese], Defense Science and Technology Industry, September: $12-14$.

Sun, L. (2007a), The development strategy and key areas of China's space sector, [in Chinese], Aerospace China, January: 3-8, 13.

Sun, L. (2007b), Peacefully use military technology, spur on economic and social development, [in Chinese], Military-Civil Dual-Use Technology and Products (11): 3-4.

Suttmeier, R. P. (1980), Science, Technology, and China's Drive for Modernization, Stanford, CA: Hoover Institution Press.

Suttmeier, R. P. and Cao, C. (1999), China faces the new industrial revolution: Achievement and uncertainty in the search for research and innovation strategies, Asian Perspective 23(3): 153-200.

Swidler, A. (2001), What anchors cultural practices, in T. R. Schatzki, K. KnorrCetina and E. von Savigny (eds), The Practice Turn in Contemporary Theory, pp. 74-92, New York: Routledge.

Tyroler-Cooper, S. and Peet, A. (2011), The Chinese aviation industry: Technohybrid patterns of development in the C919 program, Journal of Strategic Studies 34(3): 383-404. doi:10.1080/01402390.2011.574981.

Wang, N. (2011), The making of an intellectual hero: Chinese narratives of Qian Xuesen, The China Quarterly 206: 352-71. doi.org/10.1017/ S0305741011000300.

World Bank (2017), DataBank: World development indicators, Washington, DC: The World Bank. Available from: databank.worldbank.org/data/reports. aspx? source=world-development-indicators\#.

$\mathrm{Xu}$, N. (2007), Some thoughts on the space security plight, [in Chinese], Foreign Affairs Review 96: 59-63.

Yao, J. (ed.) (1996), China’s Aviation History, [in Chinese], Beijing: Dajia Press.

Yu, D. (2009), First domestic large aircraft engine test flight by 2014, [in Chinese], Caijing, 27 August. Available from: www.caijing.com.cn/2009-0827/110230032.html. 
Zeitlin, J. (1995), Flexibility and mass production at war: Aircraft manufacture in Britain, the United States, and Germany, 1939-1945, Technology and Culture 36(1): 46-79. doi.org/10.2307/3106341.

Zhang, H. (2005), Action/reaction: US space weaponization and China, Arms Control Today 35(10): 6-11.

Zhang, Q. (2003), Exploring diversified international cooperation for China's space industry, [in Chinese], Aerospace China, July: 1-4.

Zhang, Q. (2007), Future prospects of China's space development, [in Chinese], Space Exploration, September: 22-3.

Zhang, Q. (2008), Resolving to make China's large passenger aircraft soar the blue skies soon, Seeking Truth.

Zhang, Y. (ed.) (2007), Development of Aeronautical Science and Technology, [in Chinese], Century of Aeronautic Science and Technology Series, Beijing: Aviation Industries Press.

Zhu, X. (2009), The influence of think tanks in the Chinese policy process: Different ways and mechanisms, Asian Survey 49(2): 333-57. doi.org/10.1525/ as.2009.49.2.333. 
This text is taken from China's New Sources of Economic Growth: Human Capital, Innovation and Technological Change, Volume 2, edited by Ligang Song, Ross Garnaut, Cai Fang and Lauren Johnston, published 2017 by ANU Press, The Australian National University, Canberra, Australia.

dx.doi.org/10.22459/CNSEG.07.2017.12 